MCGRATH, A. \& JACKSON, G. A. (1996) Survey of neuroleptic prescribing in residents of nursing homes in Glasgow. Britlsh Medical Journal, 312, 611.

MANN, A. H., GRAHAM, N. \& ASHBY, B. (1984) Psychiatric illness in residential homes for the elderly: a survey in one London borough. Age and Ageing, 13, 257-265.

NeVILLE, P. G., BROOKE, A., BROOKE, S., et al (1995) Time for change: psychiatric morbidity in residential homes for the elderly. International Journal of Geriatric Psychiatry. 10, 561-568.
Graham A. Jackson, Senior Registrar in Psychiatry, Hairmyres Hospital, East Kilbride; and ${ }^{*}$ Donald Lyons, Clinical Director, Elderly Mental Health Services, Leverndale Hospital, 510 Crookston Road, Glasgow G53 7TU

\title{
Comparison of psychogeriatric domiciliary visit service between urban and suburban sectors
}

\author{
Arun K. Jha and Robert Lawrence
}

\begin{abstract}
This study presents a comparison between the domIcillary consultation services in urban and suburban sectors of the Croydon Health District. Urban general practitioners requested less domiciliary visits (DV) and tended to be less satistied with this service than their suburban counterparts. Sociodemographic factors such as population density and multi-ethnicity in the urban sector may be responsible for a smaller referral rate and the degree of satistaction with the psychogeriatric DV service in Croydon.
\end{abstract}

Despite recent criticism and declining trend, the domiciliary visit (DV) remains a major component of a modern psychogeriatric service (Donaldson \& Hill, 1991; Forsythe, 1991). Few studies have examined the DV service in geriatric psychiatry (e.g. Hardy-Thompson, 1992; Orrell et al, 1992), and none has looked at the service in different types of communities.

A higher number of DV requests from the southern (suburban) sector of Croydon prompted us to investigate the difference between the North (urban) and the South. This study is an attempt to evaluate and compare the DV service in urban and suburban halves of Croydon by investigating general practitioners' (GP) views of the service.

Croydon is the largest of the London boroughs with a population of 320000 people, of whom $43000(13.8 \%)$ are aged over 65 . Nearly $95 \%$ of them live independently in their own homes (Health in Croydon, 1994-95). Each half of the health district has a nearly equal population, 21000 in the North and 22000 in the South, and each has a consultant-led elderly community mental health service.

Croydon has a higher proportion of ethnic minority communities than the rest of England and Wales, with $19 \%$ of black, and $24.6 \%$ of Asian ethnic groups, and 6\% are elderly people (Health in Croydon, 1994-95). Its two halves are different in their socioeconomic and demographic characteristics. The northern-half is part of south-east London and shares its urban characteristics. It is much more densely populated than South Croydon which is suburban, containing a higher proportion of private nursing homes and more elderly people requiring special care.

\section{The study}

To obtain the vlews of GPs regarding requests for DVs for patients over 65, a questionnaire was designed on the basis of a previous study (Orrell et al, 1992). This was sent to all 170 GPs in the Croydon Health District, 97 in the North and 73 in the South. The items (Table 1) related to various aspects of the DV service on a two- to five-point scale. Data were analysed using the SPSS statistical package. 
Table 1. Number (percentage) of general practitioners responding to DV questionnaire

\begin{tabular}{llcc}
\hline Questions & $\begin{array}{l}\text { Total GPs } \\
n=113\end{array}$ & $\begin{array}{l}\text { North GPs } \\
n=64\end{array}$ & $\begin{array}{l}\text { South GPs } \\
n=49\end{array}$ \\
\hline DVs requested & $69(61)$ & $32(50)$ & $37(76)^{2}$ \\
DVs attended & $19(17)$ & $11(17)$ & $8(16)$ \\
Reasons for non-attendance' & & & \\
Unnecessary & $13(12)$ & $5(8)$ & $8(16)$ \\
Inconvenient & $11(10)$ & $3(5)$ & $8(16)$ \\
Lack of time & $41(36)$ & $27(42)$ & $14(29)$ \\
Not asked & $17(15)$ & $8(13)$ & $9(18)$ \\
Other reasons & $6(5)$ & $4(6)$ & $2(4)$ \\
Satisfied & $84(74)$ & $42(66)$ & $42(86)^{2}$ \\
DVs within 72 hours & $66(58)$ & $35(55)$ & $31(63)$ \\
Factors influencing decision to request DVs & & & \\
Consultant's opinion & $43(38)$ & $22(34)$ & $21(43)$ \\
Psychiatric emergency & $42(37)$ & $21(33)$ & $21(43)$ \\
Home circumstances influencing mental health & $38(34)$ & $24(38)$ & $14(29)$ \\
Pressure from relatives & $14(12)$ & $11(17)$ & $3(6)$ \\
Patlient's physical ill health & $15(13)$ & $7(11)$ & $8(16)$ \\
Patlient's physical disability & $16(14)$ & $6(9)$ & $10(20)$ \\
Long wait for outpatient appointment & $12(11)$ & $4(6)$ & $8(16)$ \\
To facllitate admission & $7(6)$ & $4(6)$ & $3(6)$ \\
Other factors & $9(8)$ & $5(8)$ & $4(8)$ \\
\hline
\end{tabular}

1. Twenty-five GPs did not answer; $2 . \chi^{2}$ tests significant (d.f. $=1, P<0.05$ )

\section{Findings}

Out of 170 GPs, $113(66.5 \%)$ returned the completed questionnaires, $64 / 97(66 \%)$ from the North and $49 / 73(67 \%)$ from the South. More GPs (76\%) from the South than the North (50\%) requested DVs, but less than $17 \%$ had attended any in the previous six months. Among reasons given for inability to attend, lack of time was the commonest $(36 \%)$, and more so in the North $(42 \%)$ than the South (29\%). A higher proportion of GPs in the South thought it unnecessary (16\%), inconvenient $(16 \%)$, or had not been asked to attend (18\%). The majority were satisfied with the service, but their proportion in the North was significantly less $(66 \%)$ than in the South $(86 \% ; P<0.005)$. Among GPs who requested DVs, $87 \%$ were satisfied compared to $55 \%$ who were not $(P<0.0001 ; 84 \%$ in the North and $89 \%$ in the South). Most (58\%) reported their requests were met within 72 hours; there was no significant difference between North and South.

The factor GPs considered most important in their decision to request a DV was the consultant's opinion $(38 \%)$ while the least important was to facilitate admission to psychiatric hospital (6\%). A higher proportion of GPs from the South considered psychiatric emergency (43\% versus $33 \%)$ and patient's physical disability $(20 \%$ versus $9 \%$ ) important, but the differences did not reach statistical significance.
There was an association between the request for DVs and the degree of satisfaction with the service: $60 / 90(67 \%)$ GPs who had requested any DV in the previous six months were satisfied $(P<0.0005), 86 \%$ in the North and $88 \%$ in the South.

\section{Comment}

This study highlights differences in the DV service between the two halves of Croydon, particularly frequency and rate of referral, and degree of satisfaction with the service.

That only $6 \%$ of GPs requested a DV in order to facilitate admission was far less than the $32 \%$ and $47 \%$ reported by Coupland $\&$ Todd (1985) and Hardy-Thompson et al (1992) respectively. This difference in our results may reflect a change in the style of practice in primary care as well as the development of psychiatric services towards community care models.

Mental and physical disorders frequently coexist in the elderly. In Hardy-Thompson et al's study, a higher proportion ( $n=46,54 \%)$ of GPs thought that the patient's physical disability was important in influencing their decision to request a DV. In our study, $20 \%$ suburban and $9 \%$ urban GPs felt that this was so. This discrepancy may be related to easier access to the District General Hospital by the population in the North of the borough and the presence of a special interest 
service for dementia cases run by a local geriatrician which preceded the establishment of a full-time psychogeriatric service in the same locality by two years.

Our study confirmed previous findings of a low rate of GP attendance at DVs, mainly because of lack of time or awkward timing (Hardy-Thompson et al, 1992).

Hardy-Thompson et al (1992) showed that $69.5 \%$ GPs in an outer London area were satisfied with the psychogeriatric DV service. Our study showed similar results in the urban North of the borough but satisfaction ratings were significantly higher for the suburban South. A possible explanation is that a psychogeriatric service with a complete multidisciplinary team had been established in the South one year before the same development in the North. Also, the South being geographically vast might have prevented frail and elderly patients living alone or as residents in nursing and residential homes in the area from attending the out-patient clinic. Longer out-patient lists in the South may have meant that some patients developed acute crises prior to their appointment, hence requiring urgent visits.

GPs with a high use of the service are more satisfied with the service (Orrell et al, 1992). This might have been why those GPs who had requested any DV in the previous six months were more satisfled with the service. However, there was no association between the degree of satisfaction and frequency of DV requests in the South. Nine out of 12 GPs $(75 \%)$ in the South were satisfied with the service without having requested a DV in the previous six months. These results may reflect differences in the GP population between the two sectors.

One further difference between the two sectors related to the high concentration of Asian population in the North. This ethnic group is generally underrepresented in out-patient psychiatric departments (Leff, 1988).

This study can be criticised as the views of patients, their relatives and carers were not included. But our aim was to qualify the desirability and efficiency of the DV service at the level of the network of primary and secondary care for elderly patients.
Urbanisation and better transport facilities may negatively affect rates of referrals for psychogeriatric domiciliary consultations. Despite this, and sociodemographic differences between urban and suburban sectors, our study confirmed that the DV service in Croydon is valued by GPs over and beyond expediting admissions.

\section{Acknowledgements}

The authors are grateful to Dr Klaus Bergmann for his helpful comments on earlier drafts of the article, and to GPs in Croydon for participating in this study.

\section{References}

Coupland, A. I. \& ToDD, G. B. (1985) Patterns of domiclitary consultation in Trent region. British Medical Journal, 200. 1399-1402.

DONALDSON, L. J. \& HnL, M. (1991) The domiciliary consultation service: time to take stock. British Medical Journal, so2, 449-451.

FORSYTHE, M. (1991) Domiclitary visits. Brttish Medical Journal, s02, 426-427.

HARDY-THOMPSON, C., OREL, M. W. \& BERGMANN, K. (1992) Evaluating a psychogeriatric domiclitary visit service: views of general practitioners, British Medical Joumal, s04, 421-422.

HEALTH IN CROYDON (1994-95) The Annual Report of the Director of Public Health. Croydon Health Authority.

LEFF, J. (1988) Asians in the UK. In Psychiatry Around the Globe. A Transcultural View (ed. J. Leff), pp. 197-205. London: Gaskell.

ORRELl, M. W., HARDY-ThOMPSON, C. \& BergmanN, K. (1992) Comparison between general practitioners with high or low use of a psychogeriatric domicliary visit service. International Joumal of Geriatric Psychiatry, 7, 885-889.

*Arun K. Jha, Consultant in Old Age Psychiatry, Logandene Elderly Care Unit, Ashley Close, Bennets End, Hemel Hempstead, Hertfordshire HP3 8BL; and Robert Lawrence, Consultant in Psychogeriatrics, The Bethlem and Maudsley NHS Trust, Croydon Mental Health Service, Warlingham Park Hospital, Surrey, CR6 9YR

\footnotetext{
*Correspondence
} 